\title{
The effect of irradiation temperature on damage structures in proton-irradiated zirconium alloys
}

DOI:

10.1016/j.jnucmat.2018.12.006

\section{Document Version}

Accepted author manuscript

Link to publication record in Manchester Research Explorer

\section{Citation for published version (APA):}

Topping, M., Harte, A., Ungar, H. T., Race, C., Dumbill, S., Frankel, P., \& Preuss, M. (2019). The effect of irradiation temperature on damage structures in proton-irradiated zirconium alloys. Journal of Nuclear Materials, 514, 358-367. https://doi.org/10.1016/j.jnucmat.2018.12.006

\section{Published in:}

Journal of Nuclear Materials

\section{Citing this paper}

Please note that where the full-text provided on Manchester Research Explorer is the Author Accepted Manuscript or Proof version this may differ from the final Published version. If citing, it is advised that you check and use the publisher's definitive version.

\section{General rights}

Copyright and moral rights for the publications made accessible in the Research Explorer are retained by the authors and/or other copyright owners and it is a condition of accessing publications that users recognise and abide by the legal requirements associated with these rights.

\section{Takedown policy}

If you believe that this document breaches copyright please refer to the University of Manchester's Takedown Procedures [http://man.ac.uk/04Y6Bo] or contact uml.scholarlycommunications@manchester.ac.uk providing relevant details, so we can investigate your claim.

\section{OPEN ACCESS}




\title{
The effect of irradiation temperature on damage structures in proton-irradiated zirconium alloys
}

\author{
M Topping ${ }^{1}$, A Harte ${ }^{1}$, T Ungar ${ }^{1,2}$, C P Race ${ }^{1}$, S Dumbill ${ }^{3}$, P Frankel ${ }^{1}$, M Preuss ${ }^{1}$ \\ ${ }^{1}$ Materials Performance Centre, School of Materials, The University of Manchester, \\ Manchester M13 9PL, UK \\ ${ }^{2}$ Department of Materials Physics, Eötvös University, POB 32, Hungary \\ ${ }^{3}$ National Nuclear Laboratory, Sellafield, Seascale, Cumbria, CA20 1PG, UK
}

\begin{abstract}
A study into the effects of irradiation temperature on the damage structures that form during proton-irradiation has been carried out on two commercial $\mathrm{Zr}$ alloys in order to develop a more mechanistic understanding of the effect of niobium on dislocation loop evolution. The two Zr alloys (Zircaloy-2 and Low-Sn ZIRLO ${ }^{\mathrm{TM}}$ ) were proton irradiated to a damage level of $\sim 2 \mathrm{dpa}$ at $280^{\circ} \mathrm{C}, 350^{\circ} \mathrm{C}$ and $450^{\circ} \mathrm{C}$. Detailed dislocation analysis was carried out using on-axis bright-field scanning transmission electron microscopy combined with spectral imaging and synchrotron $\mathrm{x}$-ray line profile analysis. The analysis revealed a significant difference in the effect of irradiation temperature on loop size between the two alloys. In the case of the $\mathrm{Nb}$-free $\mathrm{Zr}$-alloy (Zircaloy-2), an increase in irradiation temperature results in a marked increase in a-loop diameter, by a factor of $\sim 7.5$ from 280 to $450^{\circ} \mathrm{C}$, and a stark decrease in the dislocation line density. In contrast, the $\mathrm{Nb}$-containing $\mathrm{Zr}$-alloy (Low-Sn ZIRLO ${ }^{\mathrm{TM}}$ ) showed very little variation of loop size and line density over the same radiation temperature range. The STEMbased spectral imaging revealed irradiation-induced nano-clustering found throughout the matrix in Low-Sn ZIRLO ${ }^{\mathrm{TM}}$, which is not present in the case of Zircaloy-2. Therefore, it is proposed that $\mathrm{Nb}$ plays a crucial role in the evolution of dislocation loops in $\mathrm{Zr}$ through the formation of irradiation precipitation throughout the matrix.
\end{abstract}




\subsection{Introduction}

Zirconium alloys are used for structural components in fuel assemblies in reactor-cores due to their low thermal neutron capture cross-section and suitable structural and corrosion properties. However, one of the major life-limiting factors for these structural components is the phenomenon of irradiation induced growth (IIG). IIG is a dimensional change as a result of the introduction of line defects in the crystal structure via irradiation damage. Due to the texture of the $\mathrm{Zr}$ cladding, positive growth occurs in the axial direction and shrinkage occurs in the radial direction of the tubes [1]. This phenomenon is believed to be related to the nucleation of dislocation loops on different crystallographic planes, formed by the amalgamation of the point defects that are generated by the irradiation damage [2-4].

Two dominant types of dislocation loops form during irradiation in $\mathrm{Zr}$ alloys. The first type to form are known as a-loops, due to their $\frac{1}{3}\langle 11 \overline{2} 0\rangle$ Burgers vector and first order prismatic habit plane [5]. These dislocations form at low neutron fluences and can be seen after $\sim 3 \times 10^{23}$ neutron $\mathrm{m}^{-2}$ in recrystallised Zircaloy-2 irradiated at $300^{\circ} \mathrm{C}$ [1]. The second type to form are known as c-loops and inhabit the basal plane with a Burgers vector of $\frac{1}{6}\langle 20 \overline{2} 3\rangle[6]$. Appearance of these loops coincides with breakaway growth, which is an accelerated growth regime occurring beyond $\sim 5 \times 10^{25} \mathrm{n} \mathrm{m}^{-2}$ in recrystallised Zircaloy-2 at $\sim 565 \mathrm{~K}$ [2]. The present work focuses solely on a-loop density and morphology, as it is important for the understanding of the initial damage process, which dominates component lifetime.

Neutron-irradiation temperature has been shown to have a significant effect on IIG [710]. At low damage levels, where only a-loops are present, low temperature irradiation (i.e, irradiation temperature of $\sim 77^{\circ} \mathrm{C}$ ) result in enhanced growth strain compared with higher irradiation temperatures [10]. Northwood and Gilbert demonstrated that an increased irradiation temperature raises a-loop size in $\mathrm{Zr}$ alloys under neutronirradiation [11]; in Zircaloy-2 irradiated to $2 \times 10^{24} \mathrm{n} \mathrm{m}^{-2}$ at $283^{\circ} \mathrm{C}$, the average a-loop diameter was $8-10 \mathrm{~nm}$, whereas in a similar $\mathrm{Zr}-1.15 \mathrm{Cr}-0.1 \mathrm{Fe}$ alloy irradiated to a fluence of $8.4 \times 10^{23} \mathrm{n} \mathrm{m}^{-2}$ at $\sim 500^{\circ} \mathrm{C}$ the average diameter was $40 \mathrm{~nm}$ [11]. An increase in a-loop diameter with increasing irradiation temperature was also observed in Zircaloy-2 irradiated up to a fluence of $1 \times 10^{25} \mathrm{n} \mathrm{m}^{-2}$ and this a-loop diameter increase 
was correlated with a decrease in the dislocation line density [12]. The effect of irradiation temperature has also been studied through the use of electron-irradiation [13-15]. Most recently, Gaumé et al. demonstrated that at elevated electron-irradiation temperatures, an increase in a-loop diameter was observed in Zircaloy-4 [13].

Due to the difficulty in obtaining in-reactor materials to carry out a systematic study of irradiation temperature on dislocation loop formation and morphology, proton, heavyion and electron-irradiations have been explored [16-19]. Previous work has also demonstrated the suitability of proton-irradiation to generate dislocation loop structures similar to those obtained during neutron-irradiation [17,20-23]. In order to compensate for accelerated dose rates during proton irradiation, proton irradiation temperatures are typically higher than in-reactor temperatures. In the case of $\mathrm{Zr}$ cladding, a $40^{\circ} \mathrm{C}$ temperature increase resulting in a proton irradiation temperature of $350^{\circ} \mathrm{C}$ has been proposed [24]. This temperature offset is currently used regardless of the specific $\mathrm{Zr}$ alloy.

In the present work we investigate the combined effect of alloy chemistry and varying irradiation temperature on a-loop morphology in proton-irradiated $\mathrm{Zr}$ alloys. We accomplish this by comparing two alloys, Zircaloy-2 and Low-Sn ZIRLO ${ }^{\mathrm{TM}}$, protonirradiated to $\sim 2$ displacements per atom (dpa) at temperatures of 280,350 or $450{ }^{\circ} \mathrm{C}$. These two commercial alloys were chosen because Low-Sn ZIRLOTM contains niobium $(\mathrm{Nb})$, whereas Zircaloy-2 does not. This is of interest as $\mathrm{Nb}$ containing alloys have been shown to exhibit less growth strain for the equivalent neutron fluence compared to non $\mathrm{Nb}$-containing alloys [25-27]. A detailed quantitative characterization of the irradiation-induced defect structure has been performed using a range of transmission electron microscopy (TEM) techniques and line profile analysis (LPA) of synchrotron x-ray diffraction (SXRD) profiles. By using proton-irradiation in the present study it has been possible to carefully control and maintain the experimental conditions. For example, the two alloys were irradiated to the same damage level at a similar dose rate, based on calculations for pure Zr, which makes up 98\% of Zircaloy2 and $\sim 99 \%$ of Low-Sn ZIRLO ${ }^{\mathrm{TM}}$. Here the only major variable was the irradiation temperature; obtaining a comparable matrix of samples from a commercial reactor, in which the temperature and neutron flux profile vary with position in the fuel pile, would be extremely difficult. 


\subsection{Experimental Methods}

Recrystallised Zircaloy-2 (Zr-1.5Sn-0.1Fe-0.1Cr-0.06Ni [28]) and Low-Sn ZIRLO ${ }^{\mathrm{TM}}$ (Zr-0.1 Nb-0.7Sn-0.1Fe [29]) were irradiated with $2 \mathrm{MeV}$ protons at the University of Manchester's Dalton Cumbrian Facility, UK and at The University of Michigan Ion Beam Laboratory. Both alloys were irradiated to a proton density of $2.134 \times 10^{19}$ protons $\mathrm{cm}^{-2}$ (equivalent to $\sim 2 \mathrm{dpa}$ at $40 \%$ of the max dose depth) at three different irradiation temperatures. The temperatures were monitored during the irradiation via a thermal imaging camera and were maintained within $\pm 9{ }^{\circ} \mathrm{C}$ of the target temperature. The samples were first polished to a mirror finish in order to provide a flat surface free of deformation before undertaking the proton irradiation. The details of the irradiation experiment can be seen in Table 1. The vast majority of protons implanted in the material will stop at the Bragg peak (Figure 1) and it is assumed that due to the temperature gradient caused by the non-irradiated region of the sample, the hydrogen will diffuse further from the irradiated surface.

Table 1. Experimental parameters for proton irradiations carried out at Dalton Cumbrian Facility (DCF) and Michigan Ion Beam Laboratory (MIBL). The sample irradiated at MIBL has been previously studied in detail $[18,21,22]$.

\begin{tabular}{|c|c|c|c|c|c|c|}
\hline Facility & Sample(s) & $\begin{array}{c}\text { Irradiation } \\
\text { Temperatures }\left({ }^{\circ} \mathbf{C}\right)\end{array}$ & $\begin{array}{c}\text { Area Irradiated } \\
\left(\mathbf{m m}^{2}\right)\end{array}$ & $\begin{array}{c}\text { Average } \\
\text { Current } \\
(\mu \mathrm{A})\end{array}$ & $\begin{array}{c}\text { Irradiation } \\
\text { Time (hours) }\end{array}$ & $\begin{array}{c}\text { Damage Rate } \\
\left(\text { dpa s }^{-1}\right)\end{array}$ \\
\hline DCF & $\begin{array}{c}\text {-Low-Sn } \\
\text { ZIRLO }^{\mathrm{TM}} \\
\text {-Zircaloy-2 }\end{array}$ & $\begin{array}{l}280 \\
450\end{array}$ & 100 & 28 & 34 & $1.47 \times 10^{-5}$ \\
\hline MIBL & $\begin{array}{c}\text {-Low-Sn } \\
\text { ZIRLO }^{\mathrm{TM}} \\
\text {-Zircaloy-2 }\end{array}$ & 350 & 160 & 32 & 46 & $1.09 \times 10^{-5}$ \\
\hline
\end{tabular}

The dose calculations were performed using the SRIM software package with the "Quick" Kinchin and Pease damage calculation [30], in pure Zr with a displacement threshold energy of $40 \mathrm{eV}$. As the damage rate varies with depth (see profile in Figure 1) all TEM specimens were taken $\sim 12 \mu \mathrm{m}$ beneath the irradiated surface from the flat region providing the above quoted dpa level obtained at $40 \%$ of the depth of the predicted Bragg peak. The TEM foils were prepared via twinjet electropolishing using an electrolyte of $10 \%$ perchloric acid in methanol at $-40{ }^{\circ} \mathrm{C}$. To study the plateau region of the damage profile, $\sim 12 \mu \mathrm{m}$ was first electropolished from the irradiated surface. This was confirmed using a Keyence VK-X200K 3D Laser Scanning Microscope, after 
which the irradiated face was protected with acid-resistant lacquer before polishing the samples to perforation from the non-irradiated face.

To estimate the level of irradiation hardening, micro-hardness testing was carried out on a Struers Duramin with a Vickers indenter tip. Due to limitations in sample size, 15 indents were carried out on each specimen. The sample irradiated at $350^{\circ} \mathrm{C}$ could not be included in this analysis as the irradiated bars had already been turned into TEM foils for another study. All hardness tests were carried out at room temperature. A load of $980.7 \mathrm{~N}$ was selected, resulting in an indent depth of $\sim 4.7 \mu \mathrm{m}$. Due to the plastic zone that forms under the tip it is estimated that there will be a contribution to the hardness up to a depth of $\sim 15 \mu \mathrm{m}$ [31-33], which is still within the plateau region of the damage profile, see Figure 1. In this context it should be noted that both alloys displayed a similar grain size of $\sim 10 \mu \mathrm{m}$ for Zircaloy-2 and $\sim 8 \mu \mathrm{m}$ for Low-Sn ZIRLO ${ }^{\mathrm{TM}}$.

The bright-field scanning transmission electron microscopy (BF-STEM) imaging was performed using an FEI Talos X-FEG 80-200 KeV microscope, operated at $200 \mathrm{kV}$ with a probe current of $590 \mathrm{pA}$. This microscope is fitted with the FEI ChemiSTEM ${ }^{\mathrm{TM}}$ system, which allows for fast, high-resolution spectral imaging. The STEM imaging was carried out at the $\langle 11 \overline{2} 0\rangle$ zone axis and all defects that became invisible at $\mathbf{g}=0002$ were counted and measured as a-loops. Thickness measurements were performed using convergent beam electron diffraction (CBED) patterns and the 10\% error associated with this measurement technique has been considered. For Zircaloy-2 proton-irradiated at $280^{\circ} \mathrm{C}, 350^{\circ} \mathrm{C}$ and $450^{\circ} \mathrm{C}$ the number of dislocations loops (images) studied were 526(5), 487(5) and 300(8), respectively. For the Low-Sn ZIRLO ${ }^{\mathrm{TM}}$ alloy protonirradiated at $280^{\circ} \mathrm{C}, 350^{\circ} \mathrm{C}$ and $450^{\circ} \mathrm{C}$ the number of dislocations (images) studied were 608(5), 587(5), 623(5), respectively. These images were taken from 2-3 grains in each sample.

SXRD measurements were performed at the Diamond Light Source, UK, beamline I11 [34]. I1 1 is a high-resolution beamline with an angular resolution of $0.001^{\circ}$, a highly parallel beam, small energy spread, high flux and low background. I11 has a fast and high resolution data acquisition capacity due to the multi-analyzer crystal (MAC) detector system consisting of 5 MAC blocks, each comprising 9 detectors positioned behind individual analyzer crystals [35]. The experiment was carried out using a beam 
energy of $\sim 15 \mathrm{keV}$ (wavelength $=0.0825860 \mathrm{~nm}$ ). Due to the uneven damage profile caused by the proton-irradiation it is important to study a similar damage depth as that at which the TEM analysis was carried out. To limit the diffraction signal to this region, a reflection geometry was selected with a fixed tilt of $5^{\circ}$ resulting in a maximum penetration depth of $\sim 13 \mu \mathrm{m}$, across the $2 \theta$ range, $15^{\circ}-55^{\circ}$. It should be noted that the data collected from this set up represents material from the entire penetrated depth, with maximum signal coming from $\sim 5 \mu \mathrm{m}(\sim 1.5 \mathrm{dpa})$, in contrast to the TEM analysis only carried out at a particular depth, i.e. $12 \mu \mathrm{m}$ from the surface. An x-ray beam size of 1 $\mathrm{mm} \times 100 \mu \mathrm{m}$, which resulted in an illuminated sample surface area of $1 \times 1 \mathrm{~mm}^{2}$, was achieved through the use of slits. The samples were spun at $1200 \mathrm{rpm}$ during acquisition to improve sampling statistics.

Line profile analysis (LPA) was used to calculate dislocation densities and the arrangement of dislocations. This was carried out using the extended Convolutional Multiple Whole Profile (CMWP) software package [36-40]. CMWP has been used previously to study dislocation densities in neutron- and proton-irradiated zirconium alloys [18,41-43] using the Krivoglaz-Wilkens model [44-46], for the strain contribution to peak profiles, $I_{h k l}^{D}$ :

$$
F T\left(I_{h k l}^{D}\right)=A_{L}^{D}=\exp \left[-\rho\left(\frac{\pi b^{2}}{2}\right) L^{2} f(\eta) g^{2} C\right]
$$

where $\rho$ and $\mathbf{b}$ are the dislocation density and Burgers vector, respectively. $\mathbf{C}$ is the $h k l$ dependent contrast factor of the dislocations, and $\mathbf{g}$ is the diffraction vector, $\mathbf{g}=2 \sin \theta_{B} / \lambda$, where $\theta_{B}$ is the Bragg angle. $L$ is the Fourier variable and $f(\eta)$ is the strain function derived by Wilkens [46]. In this function $\eta=L / R_{e}$ and $R_{e}$ is the effective outer cut-off radius of the dislocations. Wilkens also introduced the dimensionless parameter, $\mathrm{M}$.

$$
M=\operatorname{Re} \sqrt{\rho}
$$

$\mathrm{M}$ is also known as the Wilkens arrangement parameter and it describes the dipole character of the dislocation network.

\subsection{Results}

The micro-hardness data of the samples before and after irradiation are displayed in Figure 2. For Zircaloy-2, irradiation to $\sim 2 \mathrm{dpa}$ at $280^{\circ} \mathrm{C}$ resulted in a hardness increase 
of almost $40 \mathrm{HV} 0.1$. When irradiated to the same dpa level but at $450^{\circ} \mathrm{C}$, the hardness increase was slightly less, about $30 \mathrm{HV} 0.1$. In the case of Low-Sn ZIRLO ${ }^{\mathrm{TM}}$ both irradiation temperatures resulted in a hardness increase of about $30 \mathrm{HV} 0.1$. This highlights a difference between the two alloys in terms of their irradiation hardening behavior and its dependence on irradiation temperature.

Figure 3 shows the a-loop dislocation structure in Zircaloy- 2 irradiated at $280^{\circ} \mathrm{C}$ (a), $350^{\circ} \mathrm{C}$ (b) and $450^{\circ} \mathrm{C}(\mathrm{c})$. The BF-STEM images were taken at the same magnification and diffraction conditions, at the $\langle 10 \overline{1} 0\rangle$ zone axis, normal to the loop habit plane. It is noticeable that at the lowest temperature (Figure 3 (a)) the a-loops are smaller and more aligned along the trace of the basal plane than at higher temperature (Figures 3(b) and (c)) with the mean diameter increasing from $9.0 \pm 1.1 \mathrm{~nm}$ to $14.9 \pm 8.0 \mathrm{~nm}$ to $66.9 \pm$ $14.2 \mathrm{~nm}$ as the irradiation temperature increases; the quoted ranges are the standard deviations of the loop sizes. It should be noted that the mean diameter is in respect of the major axis of the elliptical a-loops. Line defects can also be seen in the sample irradiated at $450^{\circ} \mathrm{C}$. These line defects were not included in the dislocation analysis.

Figure 4 is a series of BF-STEM images of Low-Sn ZIRLO ${ }^{\mathrm{TM}}$ proton-irradiated at (a) $280^{\circ} \mathrm{C}$, (b) $350^{\circ} \mathrm{C}$ and (c) $450^{\circ} \mathrm{C}$ respectively. Images were again taken at the $\langle 10 \overline{1} 0\rangle$ zone axis and are at the same magnification. The size of the a-loops changes less than in the Zircaloy-2 (Figure 3). However, there is still a slight increase in loop diameter with irradiation temperature from (a) $5.9 \pm 1.0 \mathrm{~nm}$ to (c) $8.2 \pm 0.6 \mathrm{~nm}$, with the errors representing the standard deviation of the loop sizes.

X-ray spectral imaging was carried out on the irradiated samples to investigate any possible chemical differences associated with the a-loop morphology in the two alloys. The Fe map of the Zircaloy-2 sample irradiated at $450^{\circ} \mathrm{C}$, taken at the diffraction condition $\mathbf{g}=0002$, is displayed in Figure 5(a). Rod-like Fe segregation can be seen to the left of the secondary phase particle (SPP), with a length of about $43 \mathrm{~nm}$. No Chemical segregation was observed in the matrix for the Zircaloy-2 sample irradiated at $280^{\circ} \mathrm{C}$. Figure $5(\mathrm{~b})$ and (c) are $\mathrm{Nb}$ chemical maps taken from Low-Sn ZIRLO ${ }^{\mathrm{TM}}$ irradiated at $280^{\circ} \mathrm{C}$ and $450^{\circ} \mathrm{C}$, respectively, taken from the $\langle 10 \overline{1} 0\rangle$ zone axis. In Figure 5(b), Low-Sn ZIRLO ${ }^{\mathrm{TM}}$ irradiated at $280^{\circ} \mathrm{C}$, it can be seen that there are clusters of $\mathrm{Nb}$ throughout the matrix and the clusters have a mean diameter of $1.9 \pm 1.0 \mathrm{~nm}$, which were not observed prior to irradiation. These clusters do not appear to be associated 
with a-loops. In Figure 5(c), Low-Sn ZIRLO ${ }^{\mathrm{TM}}$ irradiated at $450^{\circ} \mathrm{C}$, again $\mathrm{Nb}$ clusters are observed throughout the matrix but this time the mean diameter is about $2.5 \pm 0.9$ $\mathrm{nm}$. In comparison with these $\mathrm{Nb}$ clusters, the rod-like features observed in Zircaloy-2 are much less uniformly distributed and only associated with SPPs [47]. The chemical maps showing the absence of any segregation in the non-irradiated samples are provided as supplementary materials A.

\section{$\underline{3.1 \text { Quantitative characterization of dislocation loops }}$}

A SXRD profile for the Low-Sn ZIRLO ${ }^{\mathrm{TM}}$ sample proton-irradiated at $280^{\circ} \mathrm{C}$ is shown in Figure 6 as an example of the CMWP analysis. The full pattern analysed can be seen in Figure 6(a) with the experimental data in black and the fit generated by CMWP in red. Significant peak broadening is observed for the (1011) peak, while no significant peak broadening but asymmetries and shoulders are observed on the (0002) peak, in the irradiated sample (black profile) when viewed in a log scale, Figure $6(\mathrm{~b})$. The blue profile is from a non-irradiated Low-Sn ZIRLO ${ }^{\mathrm{TM}}$ specimen where no asymmetry is detectable. The absence of (0002) peak broadening suggest no presence of c-loops. The shoulders, particularly obvious for the (0002) reflection, have been previously observed in irradiated $\mathrm{Zr}$ alloys [48] and have been treated as a separate phase. The source of these shoulder peaks is currently not clear, but they have been investigated as part of a different study [42]. They may be a result of Huang scattering from small point defect clusters, as seen in irradiated vanadium alloys [49], however further investigations into the origin of these shoulders is currently underway.

The quantitative analysis of the a-loop diameter and line density in Zircaloy-2 and LowSn ZIRLO $^{\mathrm{TM}}$ are presented in Figure 7(a) and (b), respectively. Dislocation size, characterized by the major axis of the elliptical a-loops, was obtained from microscopy investigations and loop line densities from both microscopy and from CMWP. It can be seen from Figure 7(a) that the size of the a-loops increases dramatically in Zircaloy2 with increasing irradiation temperature. In contrast, Low-Sn ZIRLO ${ }^{\mathrm{TM}}$ only shows a slight increase in size with irradiation temperature. The standard deviation in the measurements also increases with irradiation temperature for Zircaloy-2 indicating that the dislocation size becomes less uniform at $450^{\circ} \mathrm{C}$.

Figure 7(b) shows the a-loop density calculated for both Zircaloy-2 and Low-Sn ZIRLO $^{\mathrm{TM}}$ at the various irradiation temperatures. Zircaloy-2 exhibits a dramatic 
decrease in a-loop line density with increased irradiation temperature. This trend is observed both in the TEM and using CMWP. However, in Low-Sn ZIRLO ${ }^{\text {TM }}$ a slight decrease in the line density was observed via TEM analysis and no definitive trend was seen from the analysis carried out using CMWP. From the TEM analysis the a-loop line density of Zircaloy-2 drops from $1.23 \times 10^{15} \mathrm{~m}^{-2}$ to $0.09 \times 10^{15} \mathrm{~m}^{-2}$ when increasing the irradiation temperature from $280^{\circ} \mathrm{C}$ to $450^{\circ} \mathrm{C}$, whereas Low-Sn ZIRLO ${ }^{\mathrm{TM}}$ only drops from $1.48 \times 10^{15} \mathrm{~m}^{-2}$ to $0.94 \times 10^{15} \mathrm{~m}^{-2}$. It should be noted that CMWP provides higher line density compared to TEM, up until the a-loops have reached a size larger than approximately $15 \mathrm{~nm}$.

In addition to dislocation density, CMWP can provide information about the dipole character of dislocations, represented as the Wilkens arrangement parameter, M. The $M$ value is very sensitive to the shape on the diffraction peak tails. Figure 8(a) shows how the tails of the (103) peak are affected by the different a-loop structures that develop in Zircaloy-2 when irradiated to $\sim 2 \mathrm{dpa}$ at $280^{\circ} \mathrm{C}$ and $450^{\circ} \mathrm{C}$. The larger tails associated with the sample irradiated at $280^{\circ} \mathrm{C}$ indicate a strong dipole character. In contrast, the reduced tails associated with the sample irradiated at $450^{\circ} \mathrm{C}$ indicate a weaker dipole character. Figure 8(b) depicts the value of the Wilkens arrangement parameter provided by CMWP as a function of irradiation temperature. A clear rise of $\mathrm{M}$ can be seen for Zircaloy-2 with increasing irradiation temperature while $\mathrm{M}$ seems to slightly decrease with increasing irradiation temperature for Low-Sn ZIRLO ${ }^{\mathrm{TM}}$.

\subsection{Discussion}

The overall effect of increasing the proton irradiation temperature is an increase in aloop size and decrease in the a-loop dislocation density in Zircaloy-2 but not so much in Low-Sn ZIRLO ${ }^{\mathrm{TM}}$. Buckley and Manthorpe also studied irradiation temperature effects on Zircaloy-2 and Zr-2.5Nb alloys but using electron irradiation [50]. They showed a similar trend in that both Zircaloy- 2 and $\mathrm{Zr}-2.5 \mathrm{Nb}$ decrease in a-loop number density with increasing electron-irradiation temperature. They later showed that the aloops were larger in Zircaloy-2 than in $\mathrm{Zr}-2.5 \mathrm{Nb}$, when irradiated at $500^{\circ} \mathrm{C}$ [50], in support of the present work. In the results presented here we have used two complementary techniques to study samples irradiated in carefully controlled conditions. The results have shown a systematic evolution of the dislocation structure 
and we can see that the size varies when comparing samples of the same damage level but irradiated at different temperatures.

\subsection{Irradiation temperature dependent loop size and line density}

The trend of the a-loops in Zircaloy-2 becoming larger with a higher irradiation temperature has been seen previously in neutron-irradiated $(<1 \mathrm{MeV})$ samples to fluences of $3.1 \times 10^{24} \mathrm{n} \mathrm{m}^{-2}$ and $1 \times 10^{25} \mathrm{n} \mathrm{m}^{-2}$ at $250^{\circ} \mathrm{C}$ and $400^{\circ} \mathrm{C}$, respectively [12]. This "Round-Robin" study found that there was an increase in the average a-loop size from $8.6 \mathrm{~nm}$ to $20.1 \mathrm{~nm}$ with the increased irradiation temperature. However, there was some variation in the size and densities calculated between each participant in the study and so an average of the results has been taken for discussion here.

The most dramatic difference in the a-loop morphology we observed was in Zircaloy2 when comparing the samples proton-irradiated at $280^{\circ} \mathrm{C}$ and $450^{\circ} \mathrm{C}$, Figure 3 . However, this large increase in a-loop size is not observed in Low-Sn ZIRLO ${ }^{\mathrm{TM}}$, as shown in Figure 4. The main difference between these two alloys is the presence of $\mathrm{Nb}$ in Low-Sn ZIRLO ${ }^{\mathrm{TM}}$, as the experimental conditions were identical for both. It should be noted that Zircaloy-2 contains more Sn than Low-Sn ZIRLO ${ }^{\mathrm{TM}}$ and it has been shown that $\mathrm{Sn}$ segregates in the matrix during both proton- and neutron-irradiation [21,51]. However, in a $2.3 \mathrm{dpa}$ Zircaloy-2 sample proton-irradiated at $350^{\circ} \mathrm{C}$, the $\mathrm{Sn}$ is only weakly segregated [21] and therefore is considered not to have a significant effect at the low doses studied in the present work.

Spectral imaging was conducted on the Zircaloy-2 and Low-Sn ZIRLO ${ }^{\mathrm{TM}}$ samples proton-irradiated at $280^{\circ} \mathrm{C}$ and $450^{\circ} \mathrm{C}$. As it can be seen in Figure 5, small $\mathrm{Nb}$ clusters were observed throughout the entire matrix in the $\sim 2$ dpa Low-Sn ZIRLO ${ }^{\mathrm{TM}}$ samples. However, in Zircaloy-2, Fe clustering was heterogeneous throughout the matrix (associated with SPPs) and in the form of large rods with the longest length being 42 $\mathrm{nm}$ in the case of proton-irradiation at $450^{\circ} \mathrm{C}$. We have observed similar Fe rich, rodlike precipitation in Zircaloy-2 samples proton-irradiated at $350^{\circ} \mathrm{C}[21,47]$. These rods were much smaller, at $\sim 20 \mathrm{~nm}$, than the Fe clusters observed in the Zircaloy- 2 sample irradiated here at $450^{\circ} \mathrm{C}$.

Through these observations, we propose that the $\mathrm{Nb}$ nano-clusters present in irradiated Low-Sn ZIRLO ${ }^{\mathrm{TM}}$ act as barriers for a-loop migration and thereby prevent the loops 
and point defect clusters from coalescing and coarsening. This is in contrast to Zircaloy2 (no $\mathrm{Nb}$ ) where irradiation only leads to some heterogeneous formation of nano-rods in the vicinity of SPPs, which are less effective obstacles for a-loop migration and coalescence.

Figure 7 shows that the effect of increasing irradiation temperature is to lower the dislocation line density. This trend can be seen from both TEM and CMWP analysis. It should be noted that the Zircaloy-2 sample proton-irradiated at $350^{\circ} \mathrm{C}$ has been investigated in a previous publication [22], where dislocation loop densities were also calculated. Harte et al. [22] stated the dpa of the sample studied in reference to the expected dose at $60 \%$ of depth of the Bragg peak, resulting in a quoted damage level of $2.3 \mathrm{dpa}$. However, upon further analysis, since only 12-13 $\mu \mathrm{m}$ was removed from the irradiated sample surface during sample preparation, the region studied by TEM would be expected to represent dose of $\sim 2 \mathrm{dpa}$.

The quantification of dislocation loop densities for that study was also carried out in a slightly different manner to the approach used here. While similar BF-STEM imaging was also used to study the a-loops present (also imaged from the $\langle 10 \overline{1} 0\rangle$ zone axis) loops were only counted if a clear loop nature was observed. This resulted in an a-loop line density of $0.788 \times 10^{14} \mathrm{~m}^{-2}$. However, in the work presented here all of the defects that diffracted from the $\langle 10 \overline{1} 0\rangle$ zone axis and turned invisible at $\mathbf{g}=0002$ and were circular or had a component elongated in the c-direction were counted. This means that small defects were not discounted when a clear change in contrast within the center of the loop could not be resolved. This approach resulted in a higher a-loop line density of $3.21 \times 10^{14} \mathrm{~m}^{-2}$. This discrepancy in quantifying dislocation density for the same sample highlights the subjectivity of counting dislocation loops by TEM, where variation between experimentalists is inevitable. To minimize this variability, it is extremely important to state clearly how dislocations have been counted and analysed, allowing for clear comparisons to be made with other published work. It is likely that the densities reported by Harte et al. [22] are underestimations and those in the present work are overestimations of the true value. This variation of dislocation analysis between different microscope operators, counting the same sample, is also highlighted in a blind Round-Robin experiment [12], where variations up to a factor of $\sim 5.6$ were reported. 
As well as irradiation temperature having an effect on the dislocation density it also has an effect on the size and arrangement of the a-loops. We have information regarding these changes from the TEM but also from the line profile analysis. CMWP was used to obtain information about the dipole character of the dislocation loops. The Wilkens arrangement parameter, $\mathrm{M}$, is a component in the equation used to calculate the dislocation density (Eq. 1), and gives information about the screening effects of dislocations. If $\mathrm{M}<1$ the dislocations have a strong dipole character and when $\mathrm{M}>1$ they have a weak dipole character. This information can be seen in the tails of the Bragg peak, for example if $M<1$ the tails will decay slower than if $M>1$. Figure 8 (a) shows the difference in the tails of the (103) peak in Zircaloy-2 proton irradiated at $280^{\circ} \mathrm{C}$, $350^{\circ} \mathrm{C}$ and $450^{\circ} \mathrm{C}$. It can be seen that the tails in the $280^{\circ} \mathrm{C}$ sample are the largest, suggesting a stronger dipole character. This difference in dipole character between the three samples arises from changes in the loop diameter. In support of this, it has been shown using BF-STEM imaging (Figure 3) that the a-loops are smaller in Zircaloy-2 irradiated at $280^{\circ} \mathrm{C}$ than that irradiated at $450^{\circ} \mathrm{C}$. The tails observed in Low-Sn ZIRLO ${ }^{\mathrm{TM}}$, irradiated at $280^{\circ} \mathrm{C}$ and $450^{\circ} \mathrm{C}$, do not show any significant difference. This correlates well with the observation that the a-loop size and density do not vary much between the highest and lowest irradiation temperatures investigated (Figure 4).

\subsection{Comparison between BF-STEM and CMWP dislocation analysis}

One of the enticing features of using LPA to quantify dislocation density is a reduction in subjectivity involved with counting dislocation loops in the TEM. However, care must be taken that the peak fitting stage of LPA is done with precision. The line density calculated by CMWP is $3.70 \times 10^{14} \mathrm{~m}^{-2}$ for the Zircaloy-2 sample proton-irradiated $\sim 2$ dpa at $350^{\circ} \mathrm{C}$. It has been observed in this work, Figure 7, that when the dislocation loops are $\geq 15 \mathrm{~nm}$ in diameter the line density values between TEM and CMWP agree well. However, it can also be seen that when the dislocation loops are smaller than the difference in line density between the two measurement techniques can be up to a factor of 8. This may be due to the difficulty in resolving very small loops in the TEM [52], or it could be an artifact of small loops having a very strong dipole character, which is not appropriately taken into account during the CMWP analysis. As a diffraction-based technique, CMWP will also be affected by any features that produce strain in the lattice. Therefore it may be picking up additional features compared to the loop analysis carried out in TEM [48]. However, this may provide a more representative view of changes to 
the material due to irradiation. It should be noted that the trends produced by both techniques are always comparable.

Another benefit of LPA is a larger sampling volume so that more grains are analysed than in TEM work. Commercial $\mathrm{Zr}$ alloys are heavily textured, with a split basal texture parallel to the normal of the sample surface [53]. This makes it difficult to find a suitable grain for a-loop analysis when using BF-STEM, where it is necessary for the a-axis to be parallel with the normal of the sample surface, and the TEM foil is extracted in a conventional way, i.e. in-plane. This severely limits the number of grains available for study using STEM. Little is known regarding grain-to-grain variation in dislocation populations within a single sample or orientation dependency. Jostsons et al. stated that there is significant variation in the ratio of vacancy and interstitial a-loops between grains [5]. Therefore, sampling more grains improves the statistics and averages out potential grain-to-grain variation.

\subsection{Irradiation hardening}

There have been many studies carried out in order to assess the hardening effects of irradiation damage in $\mathrm{Zr}$ alloys [54-58]. Micro-hardness tests have been performed in this work to observe the effect of irradiation temperature on irradiation-induced hardening. The irradiated Low-Sn ZIRLO ${ }^{\mathrm{TM}}$ samples do not show much variation in their hardness, which is correlated with only a slight change in a-loop line density. A much bigger change in the hardness can be seen in Zircaloy-2 at the different irradiation temperatures, which also shows a dramatic difference in a-loop density and morphology. It has been discussed previously that a-loops act as obstacles to dislocation glide [59] and therefore can be thought of in a similar way to the dispersed barrier hardening theory [55,58-61]. It is possible to estimate the expected hardness increase due to the observed dislocation densities by using the formula:

$$
\Delta \tau=\alpha G \boldsymbol{b}(N d)^{0.5}
$$

Where $\Delta \tau$ is the change in critical resolved shear stress, $\alpha$ is a dimensionless constant proportional to the pinning strength of dislocations $(0.5$ [24]), $\mathrm{G}$ is the shear modulus (33 GPa [62]), $\mathbf{b}$ is the magnitude of the a-loop Burgers vector, $\mathrm{N}$ is the number density of the dislocation loops (generated from the TEM analysis) and $d$ is the length of the major axis of the loops [54]. The predicted $\Delta \tau$ from the non-irradiated sample to the 
one irradiated at $280^{\circ} \mathrm{C}$ is $91.8 \mathrm{MPa}$ whereas the $\Delta \tau$ for the non-irradiated sample to the one irradiated at $450^{\circ} \mathrm{C}$ is $21.1 \mathrm{MPa}$. The large difference comes from the increased size and spacing of the loops with increasing irradiation temperature. This results in a ratio of the $\Delta \tau\left(450^{\circ} \mathrm{C}\right): \Delta \tau\left(280^{\circ} \mathrm{C}\right)$ to be $\sim 1: 4$, which is similar to the ratio of change in hardness observed experimentally due to the different irradiation temperature, $~ 1: 3$. This verifies the connection between hardness changes and a-loop densities, with the samples irradiated to the same dose level.

\subsection{Significance for irradiation-induced growth:}

Irradiation temperature has been shown to greatly influence irradiation-induced growth [7-10]. In the early stage of IIG, the initial growth strain reaches the saturation point more quickly at lower temperature, while at higher temperature the plateau region occurs at a higher growth strain. The observation in the present work of a higher a-loop density at low irradiation temperatures correlates well with this initial higher growth strain assuming that it is the formation of a-loops which correlates with the initial growth. The plateau region of a standard growth curve lasts longer at lower temperatures and breakaway growth is delayed in relation to higher irradiation temperatures. Similarly, Griffiths et al. showed that increasing the irradiation temperature leads to the onset of breakaway growth at lower fluences and that this breakaway growth phenomenon is correlated to the appearance of c-loops [7]. There has also been work that shows c-loops forming earlier at higher irradiation temperatures [63] and it has been suggested that this can be attributed to an increase in alloying elements in the matrix or a reduction in the stacking fault energy at higher temperatures [64].

From the a-loop densities and hardness increases presented in this work, comparisons can be drawn with the available growth data. In Zircaloy-2 breakaway growth is not predicted at $\sim 2 \mathrm{dpa}$ for either the $280^{\circ} \mathrm{C}, 350^{\circ} \mathrm{C}$ or the $450^{\circ} \mathrm{C}$ irradiation temperature and can therefore be compared to the initial growth behavior. The highest a-loop line density and hardness increase, in the Zircaloy-2 samples examined, was seen for the sample irradiated at $280^{\circ} \mathrm{C}$. This high density can be coupled with the higher growth strain observed at low irradiation temperatures for the initial growth regime [10]. As no higher damage levels have been studied here it is not possible to comment on the 
formation of c-loops and therefore the effect of proton-irradiation temperature on breakaway growth.

When comparing the growth data of Zircaloy-2 (no-Nb) with Nb-containg alloys it is clear that the addition of $\mathrm{Nb}$ results in lower growth strains [25-27]. Based on the observations made during this work the authors propose that one of the key factors behind this observation is the evenly distributed $\mathrm{Nb}$-rich precipitates formed during irradiation. It is proposed that these nano-sized precipitates act as effective barriers for the diffusion of point defect clusters and a-loops, analogous to the mechanism suggested for the irradiation resistance of ODS steels [65-67].

\section{$\underline{4.5}$ Temperature shift during proton-irradiation}

Overall it is clear that irradiation temperature has a significant effect on the irradiationinduced microstructure and mechanical properties. Proton irradiation has proven to be an extremely useful way to systematically assess the irradiation temperature sensitivity of different alloys. Furthermore, the establishment of an objective diffraction-based method of quantifying dislocations promises to be a useful tool to complement traditional TEM studies. The proton irradiations performed here in Zircaloy-2 at $350^{\circ} \mathrm{C}$ result in a similar microstructure to that seen in neutron-irradiated Zircaloy-2 [22]. Zircaloy-2 appears to be particularly sensitive to irradiation temperature and $450^{\circ} \mathrm{C}$ produces dislocations much larger than those seen under reactor conditions. The results suggest that while $350^{\circ} \mathrm{C}$ is an appropriate temperature for proton-irradiations with the dose rate applied here and the aim of imitating dislocation loops in neutron irradiation in Zircaloy-2, great care should be taken in selecting irradiation temperatures for other compositions. Also, it may be desirable in some cases to adjust irradiation temperatures to better recreate other microstructural features such as chemical segregation or SPP amorphisation. In such cases the effect on dislocation structures may be very much dependent on the alloy studied.

\subsection{Conclusion}

Proton-irradiation has been performed on Zircaloy- 2 and Low-Sn ZIRLO ${ }^{\mathrm{TM}}$ at $280^{\circ} \mathrm{C}$, $350^{\circ} \mathrm{C}$ and $450^{\circ} \mathrm{C}$. For each sample, a region reaching a dose of $\sim 2 \mathrm{dpa}$ has been studied to assess the effect of irradiation temperature on a-loop formation. The following conclusions can be made: 
- Increasing irradiation temperature results in an increase in a-loop size and a decrease in a-loop line density in Zircaloy-2, whereas Low-Sn ZIRLO ${ }^{\mathrm{TM}}$ exhibits only a slight dependence on proton irradiation temperature. This has been shown using BF-STEM imaging and XRD line profile analysis.

- The increase in a-loop size with increase irradiation temperature is dramatic in Zircaloy-2 and negligible in Low-Sn ZIRLO ${ }^{\mathrm{TM}}$. An increase from $\sim 7 \mathrm{~nm}$ to $\sim 86$ $\mathrm{nm}$ in a-loop diameter is observed between $280^{\circ} \mathrm{C}$ and $450^{\circ} \mathrm{C}$ in Zircaloy-2 compared with $\sim 6 \mathrm{~nm}$ to $\sim 9 \mathrm{~nm}$ in Low-Sn ZIRLO ${ }^{\mathrm{TM}}$.

- We propose that the difference in temperature sensitivity for a-loop formation between the two alloys is due to the presence of $\mathrm{Nb}$ in Low-Sn ZIRLO ${ }^{\mathrm{TM}}$. The homogenous distribution of irradiation-induced clustering only observed in Low-Sn ZIRLO ${ }^{\mathrm{TM}}$ provides barriers for point defect clusters and a-loops to coalesce and coarsen.

- Irradiation-induced hardening has been observed and a significant difference has been recorded in the hardness of Zircaloy-2 irradiated at $280^{\circ} \mathrm{C}$ and $450^{\circ} \mathrm{C}$. This change is believed to be a result of the change in dislocation size and density. This hardness change is similar to that calculated based on the Orowan hardening model, which takes account of the size and average spacing of the loops.

- The observation of a higher line density at lower proton irradiation temperatures correlates well with a higher growth strain observed in the literature for low temperature neutron-irradiations during the initial growth regime.

\section{Acknowledgements}

This work is funded by an EPSRC Leadership Fellowship for the study of irradiation damage in zirconium alloys [EP/I005420/1], with additional industrial contributions from National Nuclear Laboratory. The authors would like to express their gratitude to Westinghouse for suppling the non-irradiated Low-Sn ZIRLO ${ }^{\mathrm{TM}}$ material used here. The authors would like to thank Gary Was and Ovidiu Toader for their advice and use of the Michigan Ion Beam Laboratory. Also, Andrew Smith and Nicholas Mason for assistance in carrying out the proton-irradiations at the Dalton Cumbrian Facility. The 
authors would also like to express their gratitude to Stephen Thompson for assistance in preparing the I11 beamline at Diamond Light Source.

The raw data required to reproduce these findings are available to download from [link to be added once manuscript is accepted]. The data has been linked to this submission to the Journal of Nuclear Materials. 


\section{References}

[1] F. Onimus, J.L. Bechade, Radiation Effects in Zirconium Alloys, Compr. Nucl. Mater. 4 (2012) 273-246.

[2] R.B. Adamson, Effects of Neutron Irradiation on Microstructure and Properties of Zircaloy, in: Zircon. Nucl. Ind. Twelfth Int. Symp., 2000: pp. 15-31.

[3] G.J.C. Carpenter, D.O. Northwood, The Contribution of Dislocation Loops to Radiation Growth and Creep of Zircaloy-2, J. Nucl. Mater. 56 (1975) 260-266.

[4] C.H. Woo, Modeling Irradiation Growth of Zirconium and its Alloys, Radiat. Eff. Defects Solids. 144 (1998) 145-169.

[5] A. Jostsons, P.M. Kelly, R.G. Blake, The Nature of Dislocation Loops in Neutron Irradiated Zirconium, J. Nucl. Mater. 66 (1977) 236-256.

[6] R.A. Holt, R.W. Gilbert, c-Component Dislocations in Annealed Zircaloy Irradiated at about 570K, J. Nucl. Mater. 137 (1986) 185-189.

[7] M. Griffiths, R.W. Gilbert, V. Fidleris, Accelerated Irradiation Growth of Zirconium Alloys, Zircon. Nucl. Ind. Eighth Int. Symp. (1989) 658-677.

[8] M. Griffiths, R.W. Gilbert, V. Fidleris, R.P. Tucker, R.B. Adamson, Neutron Damage in Zirconium Alloys Irradiated at 644 to 710K, J. Nucl. Mater. 150 (1987) 159-168.

[9] V. Fidleris, R.P. Tucker, R.B. Adamson, An Overview of Microstructural and Experimental Factors That Affect the Irradiation Growth Behavior of Zirconium Alloys, in: Zircon. Nucl. Ind. Seventh Int. Symp., 1987: pp. 49-85.

[10] R.A. Holt, Mechanisms of Irradiation Growth of Alpha-Zirconium Alloys, J. Nucl. Mater. 159 (1988) 310-338.

[11] D.O. Northwood, R.W. Gilbert, Neutron Radiation Damage in Zirconium and its Alloys, Radiat. Eff. 22 (1974) 139-140.

[12] D.O. Northwood, R.W. Gilbert, L.E. Bahen, Characterization of Neutron Irradiation Damage in Zirconium Alloys - An International "Round Robin Experiment," J. Nucl. Mater. 79 (1979) 379-394.

[13] M. Gaumé, F. Onimus, L. Dupuy, O. Tissot, C. Bachelet, F. Mompiou, Microstructure Evolution of Recrystallized Zircaloy-4 Under Charged Particles Irradiation, J. Nucl. Mater. 495 (2017) 516-528. doi:10.1016/j.jnucmat.2017.09.004.

[14] H. Nakamichi, C. Kinoshita, K. Yasuda, S. Fukada, Formation and Growth Process of Dislocation Loops in Zircaloys under Electron Irradiation, J. Nucl. Sci. Technol. 34 (1997) 1079-1086. doi:10.1080/18811248.1997.9733790.

[15] C. Hellio, C.H. de Novion, L. Boulanger, Influence of Alloying Elements on the Dislocation Loops Created by $\mathrm{Zr}+$ Ion or by Electron Irradiation in $\alpha$ Zirconium, J. Nucl. Mater. 159 (1988) 368-378. doi:10.1016/00223115(88)90103-1. 
[16] M. Griffiths, D. Gilbon, C. Regnard, C. Lemaignan, HVEM Study of the Effects of Alloying Elements and Impurities on Radiation Damage in ZrAlloys, J. Nucl. Mater. 205 (1993) 273-283.

[17] L. Tournadre, F. Onimus, J.-L. Béchade, D. Gilbon, J.-M. Cloué, J.-P. Mardon, X. Feaugas, O. Toader, C. Bachelet, Experimental Study of the Nucleation and Growth of c-Component Loops Under Charged Particle Irradiations of Recrystallized Zircaloy-4, J. Nucl. Mater. 425 (2012) 76-82.

[18] A. Harte, T. Seymour, E.M. Francis, P. Frankel, S.P. Thompson, D. Jädernäs, J. Romero, L. Hallstadius, M. Preuss, Advances in Synchrotron X-Ray Diffraction and Transmission Electron Microscopy Techniques for the Investigation of Microstructure Evolution in Proton- and Neutron-Irradiated Zirconium Alloys, J. Mater. Res. 30 (2015) 1349-1365.

[19] Y. de Carlan, C. Regnard, M. Griffiths, Influence of Iron in the Nucleation of <c> Component Dislocation Loops in Irradiated Zircaloy-4, in: Zircon. Nucl. Ind. Elev. Int. Symp., 1996: pp. 638-653.

[20] X.T. Zu, K. Sun, M. Atzmon, L.M. Wang, L.P. You, F.R. Wan, J.T. Busby, G.S. Was, R.B. Adamson, Effect of Proton and Ne Irradiation on the Microstructure of Zircaloy 4, Philos. Mag. 85 (2005) 649-659.

[21] A. Harte, M. Topping, P. Frankel, D. Jädernäs, J. Romero, L. Hallstadius, E.C. Darby, M.Preuss, Nano-Scale Chemical Evolution in a Proton- and NeutronIrradiated Zr Alloy, J. Nucl. Mater. 487 (2017) 30-42.

[22] A. Harte, D. Jädernäs, M. Topping, P. Frankel, C.P. Race, J. Romero, L. Hallstadius, E.C. Darby, M. Preuss, The Effect of Matrix Chemistry on Dislocation Evolution in an Irradiated Zr Alloy, Acta Mater. 130 (2017) 69-82.

[23] E.M. Francis, A. Harte, P. Frankel, S.J. Haigh, D. Jadernas, J. Romero, L. Hallstadius, M. Preuss, Iron Redistribution in a Zirconium Alloy After Neutron and Proton Irradiation Studied by Energy-Dispersive X-ray Spectroscopy (EDX) Using an Aberration-Corrected (Scanning) Transmission Electron Microscope, J. Nucl. Mater. 454 (2014) 387-397.

[24] G.S. Was, Fundamentals of Radiation Materials Science, Springer, Berlin, 2007.

[25] S. Yagnik, R. Adamson, G. Kobylyansky, J.-H. Chen, D. Gilbon, S. Ishimoto, T. Fukuda, L. Hallstadius, A. Obukhov, S. Mahmood, Effect of Alloying Elements, Cold Work, and Hydrogen on the Irradiation-Induced Growth Behavior of Zirconium Alloy Variants, Zircon. Nucl. Ind. 18th Int. Symp. (2018) 748-795.

[26] V.N. Shishov, M.M. Peregud, A. V Nikulina, G.P. Kobylyansky, A.E. Novoselov, Z.E. Ostrovsky, A. V Obukhov, Influence of Structure - Phase State of $\mathrm{Nb}$ Containing $\mathrm{Zr}$ Alloys on Irradiation-Induced Growth, in: Zircon. Nucl. Ind. Fourteenth Int. Symp., 2005: pp. 666-685.

[27] V.N. Shishov, A.V. Nikulina, A. Vladimir, Influence of Neutron Irradiation on Dislocation Structure and Phase Composition of Zr-Base Alloys, in: Zircon. 
Nucl. Ind. Elev. Int. Symp., 1996: pp. 603-621.

[28] L. Hallstadius, S. Johnson, E. Lahoda, Cladding for High Performance Fuel, Prog. Nucl. Energy. 57 (2012) 71-76.

[29] J.P. Foster, H.K. Yueh, R.J. Comstock, L. Mprovement, ZIRLO Cladding Improvement, Zircon. Nucl. Ind. 15th Int. Symp. (2011) 457-470.

[30] R.E. Stoller, M.B. Toloczko, G.S. Was, A.G. Certain, S. Dwaraknath, F.A. Garner, On the Use of SRIM for Computing Radiation Damage Exposure, Nucl. Instruments Methods Phys. Res. B. 310 (2013) 75-80.

[31] P. Hosemann, D. Kiener, Y. Wang, S.A. Maloy, Issues to Consider Using Nano Indentation on Shallow Ion Beam Irradiated Materials, J. Nucl. Mater. 425 (2012) 136-139.

[32] D. Kiener, R. Pippan, C. Motz, H. Kreuzer, Microstructural Evolution of the Deformed Volume Beneath Microindents in Tungsten and Copper, Acta Mater. 54 (2006) 2801-2811.

[33] S. Harvey, H. Huang, S. Venkataraman, W.W. Gerberich, Microscopy and Microindentation Mechanics of Single Crystal Fe-3 wt. \% Si: Part 1. Atomic Force Microscopy of a Small Indentation, J. Mater. Res. 8 (1993) 1291-1299.

[34] S.P. Thompson, J.E. Parker, J. Potter, T.P. Hill, A. Birt, T.M. Cobb, F. Yuan, C.C. Tang, Beamline I1 1 at Diamond: a new instrument for high resolution powder diffraction., Rev. Sci. Instrum. 80 (2009) 75107.

[35] N. Tartoni, S.P. Thompson, C.C. Tang, B.L. Willis, G.E. Derbyshire, A.G. Wright, S.C. Jaye, J.M. Homer, J.D. Pizzey, A.M.T. Bell, High-Performance X-ray Detectors for the New Powder Diffraction Beamline I11 at Diamond, J. Synchrotron Radiat. 15 (2007) 43-49.

[36] G. Ribárik, T. Ungár, J. Gubicza, MWP-fit : a Program for Multiple WholeProfile Fitting of Diffraction Peak Profiles by ab initio Theoretical Functions, J. Appl. Crystallogr. (2001) 669-676.

[37] G. Ribárik, J. Gubicza, T. Ungár, Correlation Between Strength and Microstructure of Ball-Milled Al-Mg Alloys Determined by X-ray Diffraction, Mater. Sci. Eng. A. 387-389 (2004) 343-347.

[38] J. Gubicza, G. Ribárik, G.. Goren-Muginstein, A.. Rosen, T. Ungár, The Density and the Character of Dislocations in Cubic and Hexagonal Polycrystals Determined by X-ray Diffraction, Mater. Sci. Eng. A. (2001) 60-63.

[39] L. Balogh, G. Ribárik, T. Ungár, Stacking Faults and Twin Boundaries in FCC Crystals Determined by X-Ray Diffraction Profile Analysis, J. Appl. Phys. 100 (2006) 23512.

[40] L. Balogh, G. Tichy, T. Ungár, Twinning on Pyramidal Planes in Hexagonal Close Packed Crystals Determined Along with Other Defects by X-Ray Line Profile Analysis, J. Appl. Crystallogr. 42 (2009) 580-591.

[41] L. Balogh, D.W. Brown, P. Mosbrucker, F. Long, M.R. Daymond, Dislocation 
Structure Evolution Induced by Irradiation and Plastic Deformation in the $\mathrm{Zr}$ 2.5Nb Nuclear Structural Material Determined by Neutron Diffraction Line Profile Analysis, Acta Mater. 60 (2012) 5567-5577.

[42] T. Seymour, Synchrotron X-Ray Diffraction Peak Profile Analysis of Neutronand Proton-Irradiated Zirconium Alloys, The University of Manchester, 2016.

[43] M. Topping, T. Ungár, C.P. Race, A. Harte, A. Garner, F. Baxter, S. Dumbill, P. Frankel, M. Preuss, Investigating the Thermal Stability of IrradiationInduced Damage in a Zirconium Alloy With Novel In Situ Techniques, Acta Mater. 145 (2018) 255-263.

[44] M.A. Krivoglaz, Theory of X-Ray and Thermal Neutron Scattering by Real Crystals, Plenum Press, New York, 1969.

[45] M.A. Krivoglaz, X-Ray and Neutron Diffraction in Non Ideal Crystals, Springer-Verlag, Berlin, 1996.

[46] M. Wilkens, The Determination of Density and Distribution of Dislocations in Deformed Single Crystals from Broadened X-Ray Diffraction Profiles, Phys. Status Solidi A. 359 (1970) 359-370.

[47] M. Topping, A. Harte, P. Frankel, G. Sundell, M. Thuvander, H.O. Andrenn, D. Jadernas, P. Tejland, J. Romero, E.C. Darby, S. Dumbill, L. Hallstadius, M. Preuss, The Effect of Iron on Dislocation Evolution in Model and Commercial Zirconium Alloys, Zircon. Nucl. Ind. 18th Int. Symp. (2018) 796-820.

[48] T. Seymour, P. Frankel, L. Balogh, T. Ungár, S.P. Thompson, D. Jadernas, J. Romero, L. Hallstadius, M.R. Daymond, G. Ribárik, M. Preuss, Evolution of Dislocation Structure in Neutron Irradiated Zircaloy-2 Studied by Synchrotron X-ray Diffraction Peak Profile Analysis, Acta Mater. 126 (2017) 102-113.

[49] K. Huang, X-Ray Reflexions From Dilute Solid Solutions, R. Soc. London Ser. A, Math. Phys. Sci. (1946) 102-117. doi:10.1098/rspa.1983.0054.

[50] S.N. Buckley, S.A. Manthorpe, Dislocation Loop Nucleation and Growth in Zirconium-2.5wt\% Niobium Alloy Durning $1 \mathrm{MeV}$ Electron Irradiation, 90 (1980) 169-174.

[51] G. Sundell, M. Thuvander, P. Tejland, M. Dahlback, L. Hallstadius, H.O. Andrenn, Redistribution of Alloying Elements in Zircaloy-2 After In-Reactor Exposure, J. Nucl. Mater. 454 (2014) 178-185.

[52] B.C. Larson, F.W. Young, X-ray Diffuse Scattering Study of Irradiation Induced Dislocation Loops in Copper, Phys. Status Solidi. 104 (1987) 273286.

[53] E. Tenckhoff, Review of Deformation Mechanisms, Texture , and Mechanical Anisotropy in Zirconium and Zirconium Base Alloys, J. ASTM Int. 2 (2011) $25-50$.

[54] A. Boyne, C. Shen, R. Najafabadi, Y. Wang, Numerical simulation of irradiation hardening in Zirconium, J. Nucl. Mater. 438 (2013) 209-217. 
[55] F. Onimus, I. Monnet, J.. Béchade, C. Prioul, P. Pilvin, A Statistical TEM Investigation of Dislocation Channeling Mechanism in Neutron Irradiated Zirconium Alloys, J. Nucl. Mater. 328 (2004) 165-179.

[56] F. Onimus, Investigation of Neutron Radiation Effects on the Mechanical Behavior of Recrystallized Zirconium Alloys, J. Nucl. Mater. 358 (2006) 176189.

[57] T. Torimaru, T. Yasuda, M. Nakatsuka, Changes in Mechanical Properties of Irradiated Zircaloy-2 Fuel Cladding Due to Short Term Annealing, J. Nucl. Mater. 238 (1996) 169-174.

[58] J. Ribis, F. Onimus, J.-L. Béchade, S. Doriot, A. Barbu, C. Cappelaere, C. Lemaignan, Experimental Study and Numerical Modelling of the Irradiation Damage Recovery in Zirconium Alloys, J. Nucl. Mater. 403 (2010) 135-146.

[59] C. Regnard, B. Verhaeghe, F. Lefebvre-Joud, C. Lemaignan, Activated Slip Systems and Localized Straining of Irradiated $\mathrm{Zr}$ Alloys in Circumferential Loadings, Zircon. Nucl. Ind. Thirteen. Int. Symp. (2002) 384-399.

[60] F. Onimus, J. Béchade, A polycrystalline modeling of the mechanical behavior of neutron irradiated zirconium alloys, J. Nucl. Mater. 384 (2009) 163-174.

[61] C. Deo, C. Tomé, R. Lebensohn, S. Maloy, Modeling and Simulation of Irradiation Hardening in Structural Ferritic Steels for Advanced Nuclear Reactors, J. Nucl. Mater. 377 (2008) 136-140.

[62] M. Griffiths, A Review of Microstructure Evolution in Zirconium Alloys During Irradiation, J. Nucl. Mater. 159 (1988) 190-218.

[63] A. Jostsons, R.G. Blake, P.M. Napier, K. Farrell, Faulted loops in NeutronIrradiated Zirconium, J. Nucl. Mater. 68 (1977) 267-276.

[64] P.C.J. Gallagher, The influence of alloying, temperature, and related effects on the stacking fault energy, Metall. Trans. 1 (1970) 2429-2461.

[65] G.R. Odette, M.J. Alinger, B.D. Wirth, Recent Developments in IrradiationResistant Steels, Annu. Rev. Mater. Res. 38 (2008) 471-503.

[66] R. Schaublin, A. Ramar, N. Baluc, V. de Castro, M.A. Monge, T. Leguey, N. Schmid, C. Bonjour, Microstructural Development Under Irradiation in European ODS Ferritic/Martensitic Steels, J. Nucl. Mater. 351 (2006) 247-260.

[67] S. Ukai, M. Fujiwara, Perspective of ODS Alloys Application in Nuclear Environments, J. Nucl. Mater. 307-311 (2002) 749-757. 


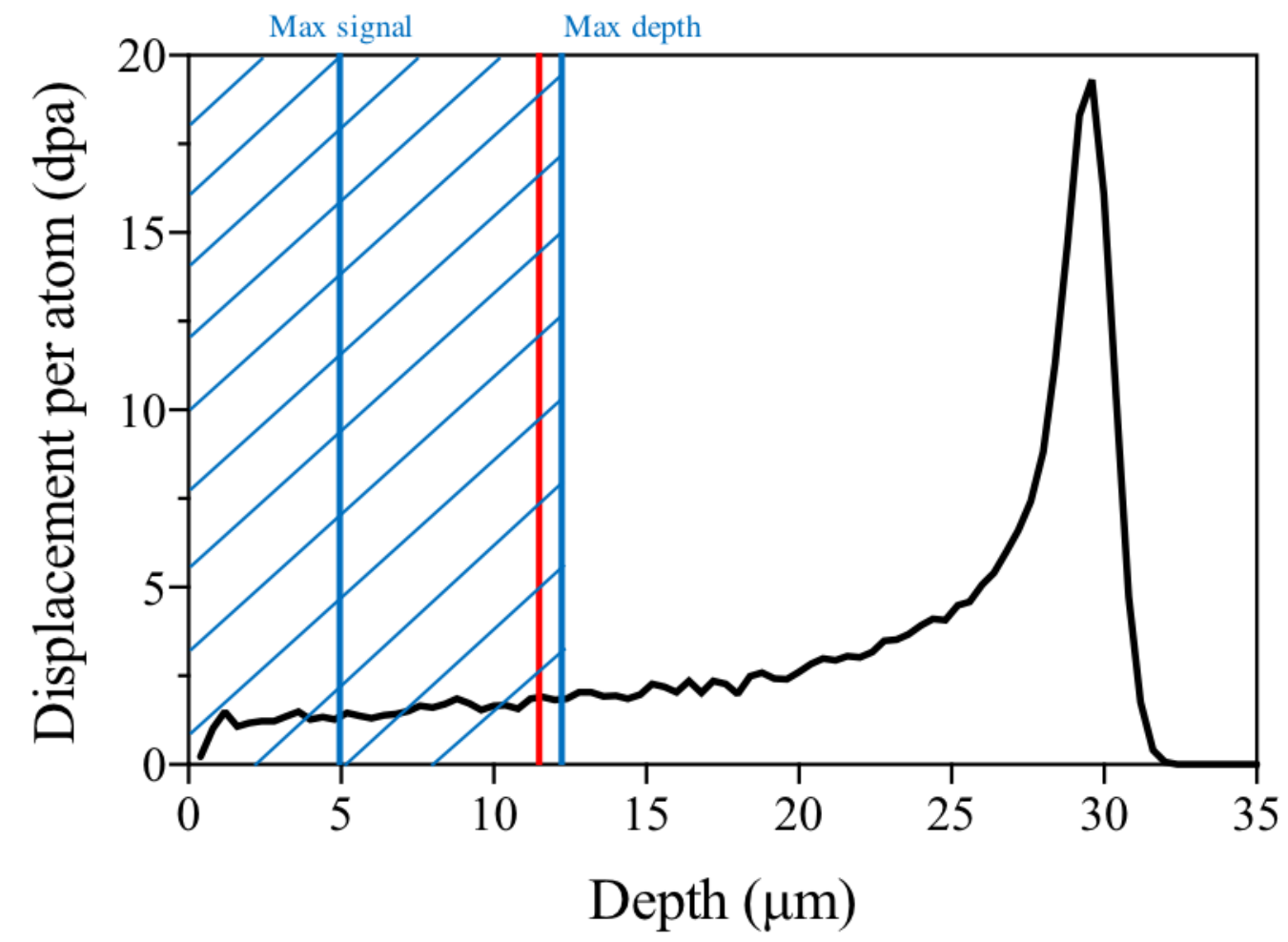

Figure 1. Damage profiles generated using SRIM for pure Zr calculated using the "Quick" method. The simulation was carried out using $2 \mathrm{MeV}$ protons and a displacement threshold energy of $40 \mathrm{eV}$ for $\mathrm{Zr}$. The calculation of dpa was carried out assuming a constant current density of $0.1875 \mu \mathrm{A} \mathrm{mm} \mathrm{m}^{-2}$ with a damage rate of $1.3 \times 10^{-5} \mathrm{dpa} \mathrm{s}^{-1}$. The red vertical line represents the depth at which samples were prepared for TEM studies $(\sim 12 \mu \mathrm{m}$ from the sample surface), and the blue hatched area represents the depth sampled via SXRD. The maximum penetration of the X-rays and the depth from which the maximum intensities of diffracted $\mathrm{x}$-rays originate are indicated.

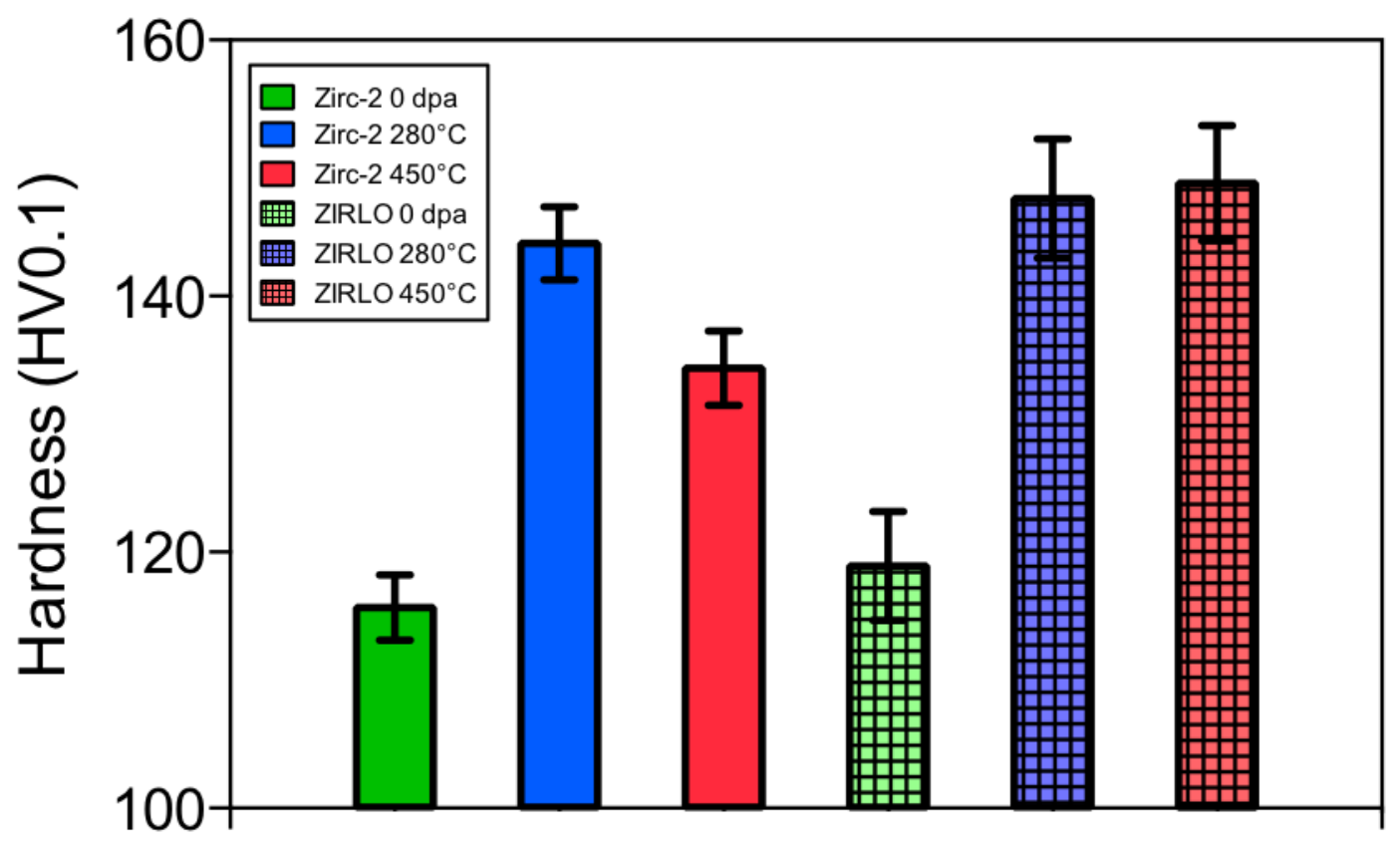

Figure 2. Vickers hardness of Zircaloy-2 and Low-Sn ZIRLOTM proton-irradiated to $\sim 2$ dpa at various irradiation temperatures. Green represents $0 \mathrm{dpa}$, blue irradiated at $280^{\circ} \mathrm{C}$ and red irradiated at $450^{\circ} \mathrm{C}$. The block colours represent Zircaloy-2 whilst the hatched pattern represents Low-Sn ZIRLO ${ }^{\mathrm{TM}}$. Error bars represent the standard deviation of the measurements. 

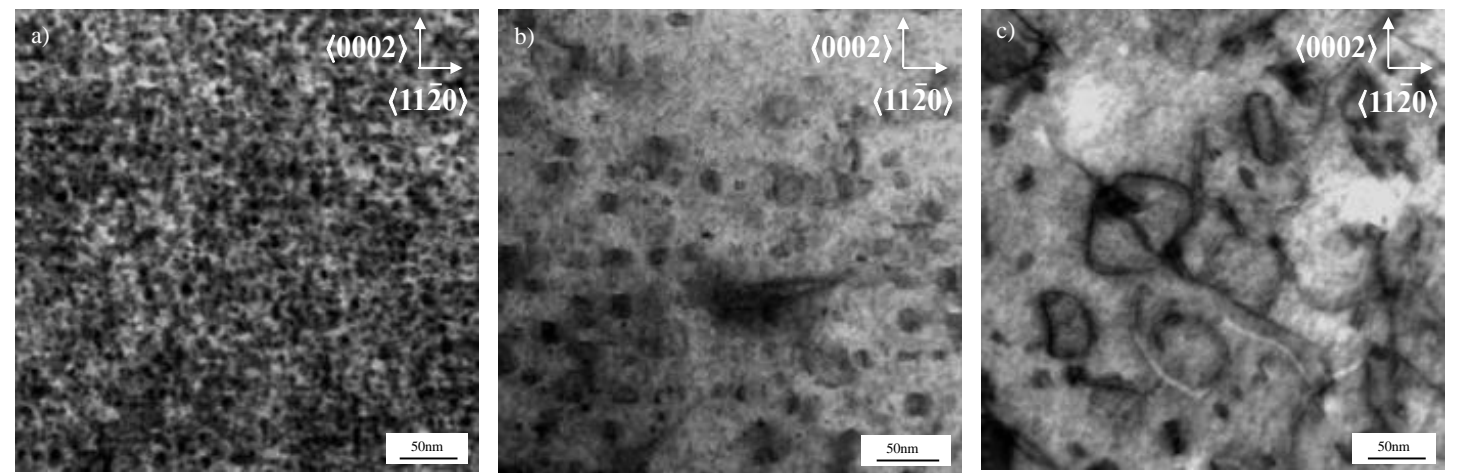

Figure 3. BF-STEM images of $\sim 2$ dpa Zircaloy-2 taken at the $<10 \overline{1} 0>$ zone axis at different irradiation temperatures. a) $280^{\circ} \mathrm{C} \mathrm{b}$ ) $350^{\circ} \mathrm{C}$ (A hydride can be seen in the middle of the image along the trace of the basal plane) c) $450^{\circ} \mathrm{C}$.
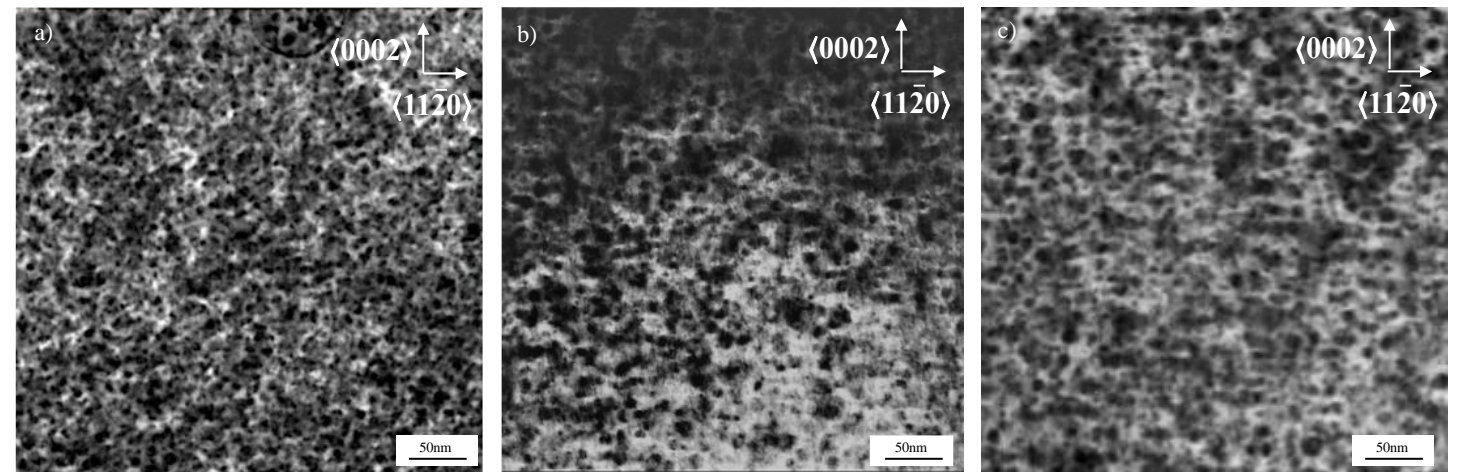

Figure 4. BF-STEM images of $\sim 2$ dpa Low-Sn ZIRLO ${ }^{\mathrm{TM}}$ taken at the $\langle 10 \overline{1} 0\rangle$ zone axis at different irradiation temperatures. a) $280^{\circ} \mathrm{C}$ b) $350^{\circ} \mathrm{C} \mathrm{c}$ ) $450^{\circ} \mathrm{C}$.
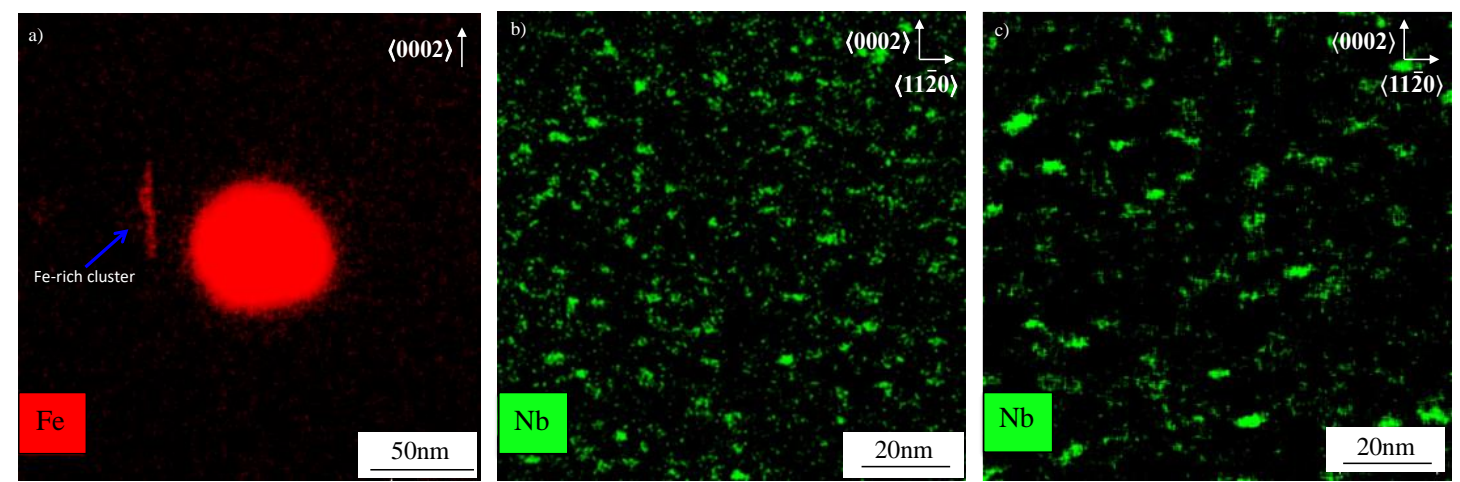

Figure 5. a) Fe Chemical map taken of a $\mathrm{Zr}$-Fe-Cr SPP in the $\sim 2$ dpa Zircaloy-2 sample irradiated at $450^{\circ} \mathrm{C}$. An Fe rich rod-like structure can be seen to the left of the SPP, highlighted with an arrow. b) Nb Chemical map taken from the $\sim 2$ dpa Low-Sn ZIRLO ${ }^{\mathrm{TM}}$ sample, irradiated at $280^{\circ} \mathrm{C}$, taken from the $\langle 10 \overline{1} 0\rangle$ zone axis. c) $\mathrm{Nb}$ chemical map of the $\sim 2$ dpa Low-Sn ZIRLO ${ }^{\mathrm{TM}}$ sample, irradiated at $450^{\circ} \mathrm{C}$. 

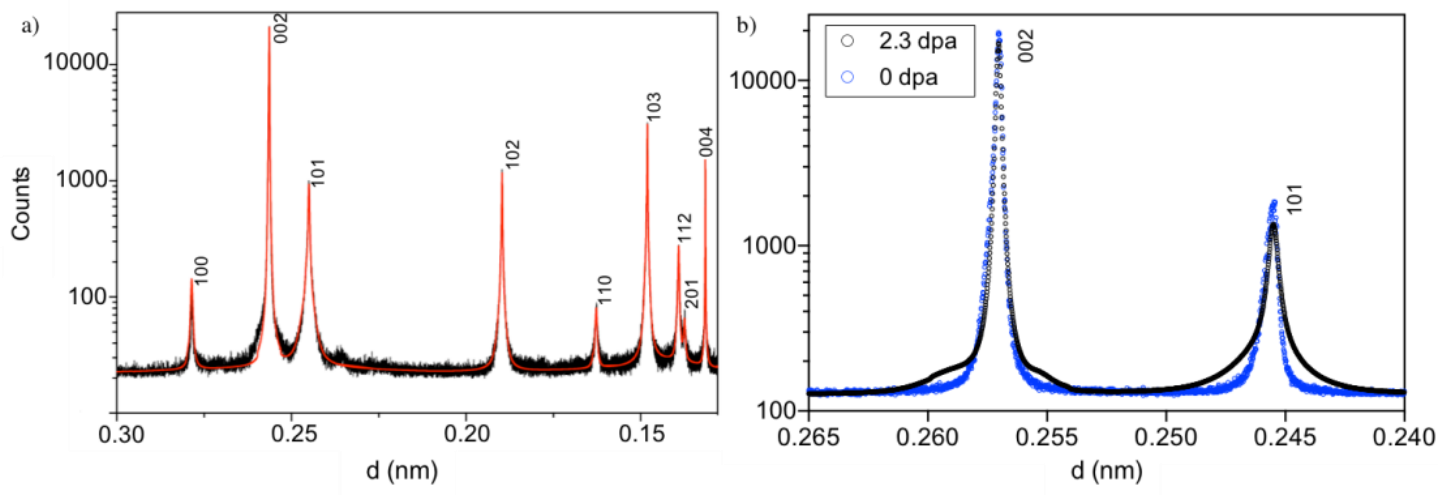

Figure 6. The SXRD profile for the $\sim 2$ dpa Low-Sn ZIRLO ${ }^{\mathrm{TM}}$ sample proton-irradiated at $280^{\circ} \mathrm{C}$ analysed by CMWP. The black open circles represent the experimental data and the red line is the simulated fit generated by CMWP. a) The full $2 \theta$ range analysed is displayed. b) The intensity of the (0002) and (1011) peaks are displayed on a log scale. The blue profile represents a non-irradiated recrystallised Low-Sn ZIRLO ${ }^{\mathrm{TM}}$ sample. The black profile is from the 1.8 dpa Low-Sn ZIRLO ${ }^{\mathrm{TM}}$ sample proton-irradiated at $280^{\circ} \mathrm{C}$ Shoulder peaks can be seen at the base of the (0002) peak in the irradiated sample.
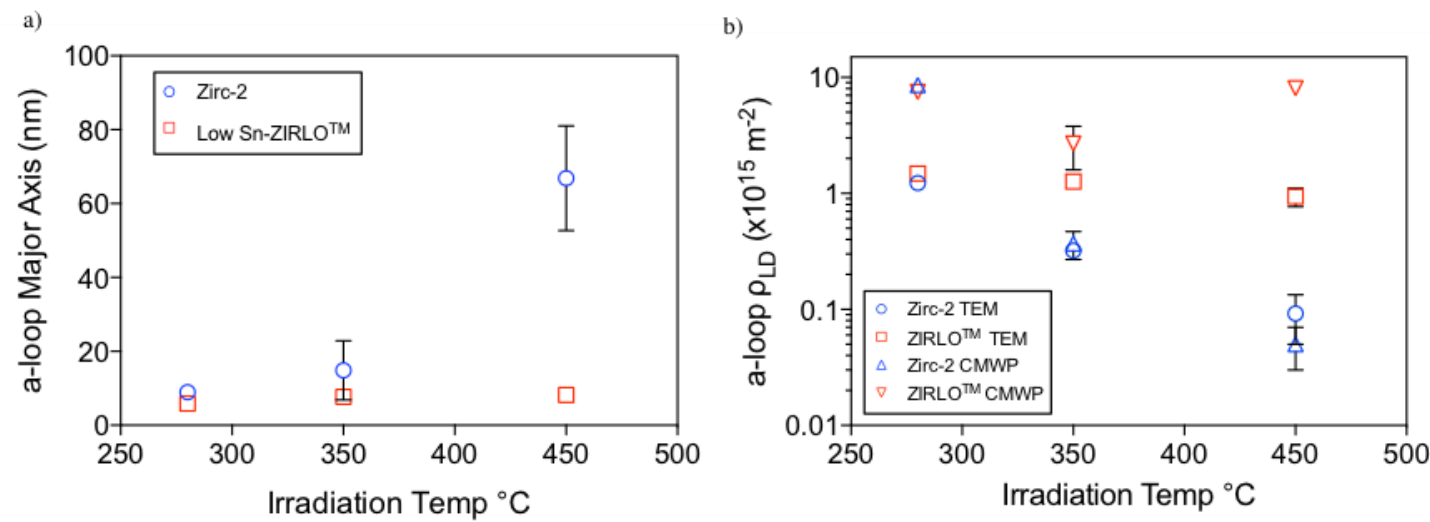

Figure 7. In both graphs blue circles represent Zircaloy-2 and red squares represent Low-Sn ZIRLO ${ }^{\text {TM }}$, analysed using STEM. Error bars represent standard deviation in measurements. Error bars smaller than the symbol size are not shown. a) a-loop diameter vs irradiation temperature. b) a-loop line density vs irradiation temperature. Blue triangles represent Zircaloy-2 and the red inverse triangles represent ZIRLO ${ }^{\mathrm{TM}}$ analysed using CMWP. 
a)

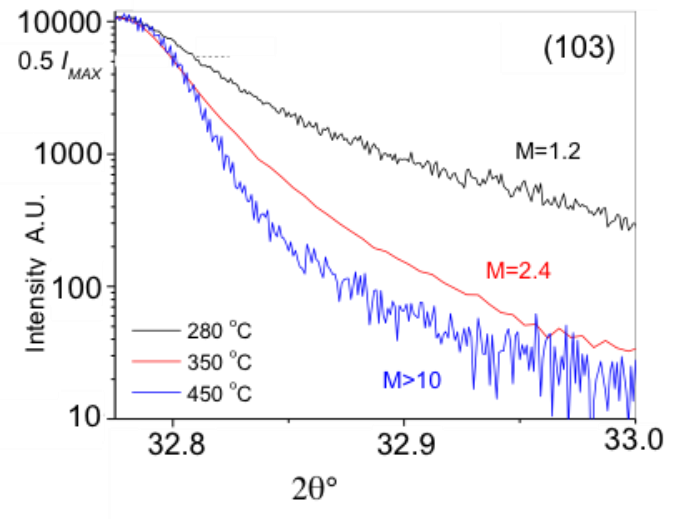

b)

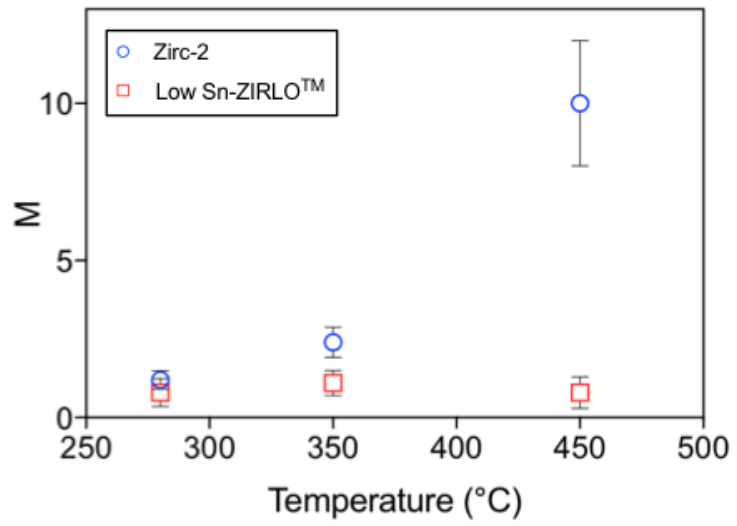

Figure 8. Effect of the dipole character of the a-loops found in Zircaloy-2 proton-irradiated at $280^{\circ} \mathrm{C}, 350^{\circ} \mathrm{C}$ and $450^{\circ} \mathrm{C}$. a) Half of the (103) peak can be seen for all three irradiation temperatures. The peaks have been normalised to allow for a comparison of the tails. The blue line represents the $280^{\circ} \mathrm{C}$ sample, the red line represents the $350^{\circ} \mathrm{C}$ sample and the black line represents the $450^{\circ} \mathrm{C}$ sample. b) Plot of the Wilkens arrangement parameter calculated using CMWP. Open blue circles represent Zircaloy-2, open red squares represent Low-Sn ZIRLO ${ }^{\mathrm{TM}}$. When M $>10$ the dipole character is so weak no changes in the analysis are observed. Error bars represent the standard deviation of the measurements.
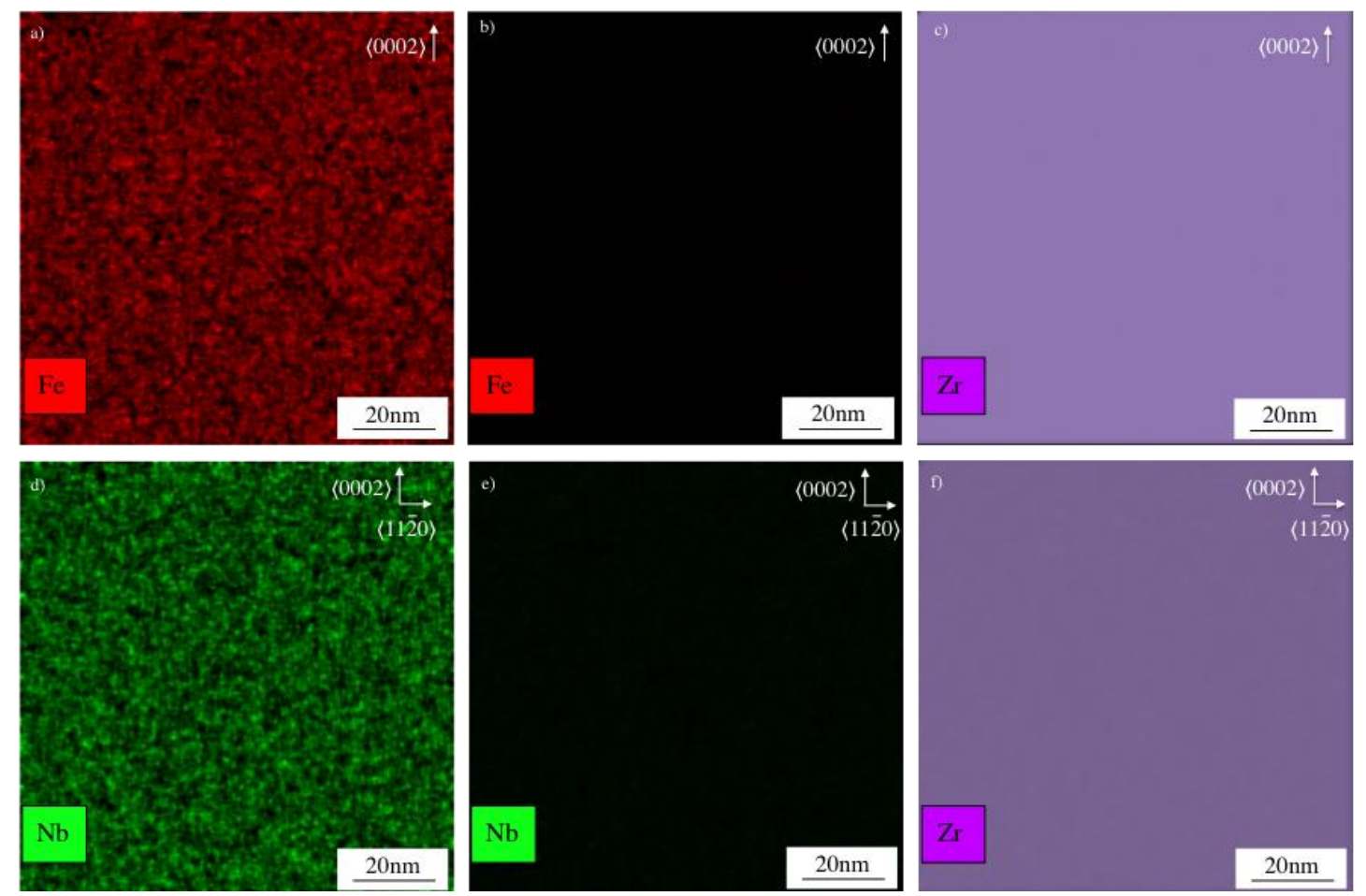

Supplementary materials A. a-c) Chemical maps of non-irradiated Zircaloy-2. No chemical segregation is observed. a) Fe Chemical map (raw data). b) Quantified Fe map. c) Quantified Zr map. d-f) Chemical maps of non-irradiated Low-Sn ZIRLO ${ }^{\mathrm{TM}}$. No chemical segregation is observed. d) $\mathrm{Nb}$ Chemical map (raw data). e) Quantified Nb map. f) Quantified $\mathrm{Zr}$ map. 